\section{POSTINFARCTION VENTRICULAR SEPTAL RUPTURE: REPAIR BY ENDOCARDIAL PATCH WITH INFARCT EXCLUSION}

A novel operative technique for postinfarction ventricular septal defect has been used in 44 consecutive patients. The operation consists of excluding rather than excising the infarcted septum and ventricular walls. This is accomplished by performance of a left ventriculotomy through the infarcted muscle and securing a glutaraldehyde-fixed bovine pericardium patch to the endocardium of the left ventricle all around the infarcted myocardium. The ventriculotomy is simply closed over the pericardial patch. There were 21 men and 23 women whose mean age was $69 \pm 7$ years. Twenty-nine patients were in cardiogenic shock at the time of operation. All patients had Doppler echocardiography and coronary angiography before operation. All but two patients were operated on during the acute phase of the myocardial infarction. There were six operative deaths. Postoperative complications included renal failure in $\mathbf{1 0}$ patients and respiratory failure in $\mathbf{1 8}$. Severe right ventricular dysfunction was the only independent predictor of operative mortality. Patients have been followed up for a mean of $40 \pm 34$ months. There have been six late deaths and three of these were because of cardiac problems. The actuarial survival at 6 years was $66 \% \pm 7 \%$. Only one patient had a small residual ventricular septal defect. Late postoperative assessment of ventricular function by echocardiography revealed that most patients had normal or mild impairment of right ventricular function and mild or moderate impairment of left ventricular function. Repair of acute postinfarction ventricular septal defect by endocardial patch with infarct exclusion of the left ventricle probably avoids additional damage to the right ventricle, remodels the acutely infarcted left ventricle, and enhances survival. (J THORAC CARDIOVASC SuRg 1995;110:1315-22)

Tirone E. David, MD, Laura Dale, RN (by invitation), and Zhao Sun, BA (by invitation), Toronto, Ontario, Canada eft ventricular wall rupture is the cause of death Lin approximately one third of all patients who have a fatal acute myocardial infarction. ${ }^{1,2}$ Most of the ventricular ruptures occur in the free wall of the left ventricle and these usually are fatal. ${ }^{1-4}$ In approximately $15 \%$ to $20 \%$ of the cases the rupture occurs in the interventricular septum ${ }^{3,4}$ and this is also often fatal unless surgically treated. ${ }^{5,6}$

Operation for postinfarction rupture of the interventricular septum is reportedly associated with high

From the Division of Cardiovascular Surgery of The Toronto Hospital and the University of Toronto, Toronto, Ontario, Canada.

Read at the Seventy-fifth Annual Meeting of The American Association for Thoracic Surgery, Boston, Mass., April 23-26, 1995.

Address for reprints: Tirone E. David, MD, 200 Elizabeth St., 13EN219, Toronto, Ontario, Canada M5G 2 C4.

Copyright $(C) 1995$ by Mosby-Year Book, Inc.

$0022-5223 / 95 \$ 5.00+0 \quad \mathbf{1 2 / 6 / 6 6 8 2 2}$ operative mortality when done during the acute phase of the myocardial infarction. ${ }^{6-8}$ Operative procedures to correct acute septal rupture have consisted of infarctectomy and reconstruction of the septum and ventricular walls with one or more Dacron fabric patches. ${ }^{9,} 10$

In 1987 we introduced a new operative procedure whereby no infarctectomy was done and the left ventricular cavity was excluded from the infarcted myocardium with a pericardial patch sutured to the endocardium of the left ventricle. ${ }^{11,12}$ This operative procedure has now been applied in 44 consecutive patients whose cases are described in this report.

\section{Patients and methods}

From May 1987 to January 1995, 45 patients were referred to one of us for surgical treatment of postinfarction ventricular septal defect (VSD). One patient was not accepted for operation because of advanced age and 
Table I. Preoperative clinical profile of patients with postinfarction VSD

\begin{tabular}{lc}
\hline & No. of patients $(\%)$ \\
\hline Electrocardiogram & \\
Sinus rhythm & $39(89)$ \\
Atrial fibrillation & $3(7)$ \\
Complete heart block & $2(4)$ \\
NYHA functional class & \\
II & $1(2)$ \\
III & $1(2)$ \\
IV & $42(95)$ \\
Cardiogenic shock & $29(66)$ \\
Location of VSD & \\
Anterior & $22(50)$ \\
Posterior & $22(50)$ \\
Left ventricular function & \\
Grade 2 & $9(20)$ \\
Grade 3 & $28(64)$ \\
Grade 4 & $7(16)$ \\
Right ventricular function & $10(23)$ \\
Grade 2 & $24(54)$ \\
Grade 3 & $10(23)$ \\
Grade 4 & \\
Coronary artery disease & $12(27)$ \\
Single vessel & $15(34)$ \\
Double vessel & $17(39)$ \\
Triple vessel &
\end{tabular}

NYHA, New York Heart Association.

multiple associated diseases. Forty-four patients were operated on. Forty-two were referred during the acute phase of the myocardial infarction and were operated on soon after the septal rupture: 18 (41\%) within 24 hours, 17 ( $38 \%$ ) within 2 to 7 days, and $7(16 \%)$ within 8 to 21 days. Two patients were referred to us 6 months and 10 years, respectively, after the myocardial infarction. The septal rupture occurred between 1 and 19 days after the acute myocardial infarction, with a mean of $3 \pm 4$ days.

There were 21 men and 23 women whose mean age was $69 \pm 7$ years (range 48 to 84 years). Table I shows the preoperative clinical profile of these 44 patients. Left-toright shunt was measured by oximetry in 39 patients and the mean value was $2.7 \pm 1.4: 1$ (range $1.5: 1$ to $10: 1$ ). An intraaortic balloon pump was inserted preoperatively in 29 patients with cardiogenic shock and in 2 patients with severe congestive heart failure. Eight patients required assisted ventilation during the resuscitative process before operation. A left ventricular assist device (Hemopump, Johnson \& Johnson Interventional Systems, Sacramento, Calif.) was inserted in one moribund patient during the work-up for shock. Right and left ventricular functions were qualitatively assessed by echocardiography in all patients and graded from 1 (normal) to 4 (severe impairment) as shown in Table II.

The following variables were tested for their significance as predictors of operative and late mortality: age older than 70 years, sex, single or multivessel disease, right and left ventricular function, cardiogenic shock, VSD location, and the need for renal dialysis. These variables were tested by $\mathrm{X}^{2}$ or Fisher's exact test where appropriate;
Table II. Preoperative left and right ventricular function assessed by echocardiography

\begin{tabular}{lrrrrrr} 
& \multicolumn{2}{c}{ Anterior VSD } & & \multicolumn{2}{c}{ Posterior VSD } \\
\cline { 2 - 3 } Function & LV & $R V$ & & LV & $R V$ \\
\hline Grade 2 & 1 & 9 & & 8 & 1 \\
Grade 3 & 14 & 10 & & 14 & 14 \\
Grade 4 & 7 & 3 & & 0 & 7 \\
\hline
\end{tabular}

$L V$, Left ventricle; $R V$, right ventricle.

the statistically significant variables were entered in a logistic regression analysis to determine their independent value. The Kaplan-Meier method was used to calculate the actuarial survival.

Operative technique. Myocardial revascularization was done before the repair of the VSD in patients with multivessel coronary artery disease. A marginal branch of the right coronary artery in patients with posterior VSD or a diagonal branch of the left anterior descending artery in patients with anterior VSD was grafted if they were diseased and supplying noninfarcted muscle.

In patients with anterior VSD, an incision was made in the apex of the left ventricle 1 to $2 \mathrm{~cm}$ from and parallel to the anterior descending artery, and 1 to $2 \mathrm{~cm}$ from it, right through the infarcted muscle. The VSD was located and the margins of the infarcted muscle were identified. A glutaraldehyde-fixed bovine pericardial patch was tailored in the shape of the left ventricular infarction. The patch was oval and measured approximately $4 \times 6 \mathrm{~cm}$ in most patients. The pericardial patch was then sutured to the lower part of the noninfarcted endocardium of the interventricular septum with a continuous 3-0 polypropylene suture as shown in Fig. 1. The patch was also sutured to the noninfarcted endocardium of the anterolateral ventricular wall. If the infarct involved the base of the anterior papillary muscle, the suture was brought outside of the heart and buttressed on a strip of bovine pericardium or Teflon felt applied to the epicardial surface of the left ventricle. Once the patch was completely secured to the endocardium of the left ventricle, the left ventricular cavity became largely excluded from the infarcted myocardium. The ventriculotomy was simply closed over two strips of bovine pericardium or Teflon felt as illustrated in Fig. 1. No infarctectomy was done unless the necrotic muscle along the ventriculotomy was sloughing at the time of its closure.

In patients with posterior VSD an incision was made in the inferior wall of the left ventricle 1 or $2 \mathrm{~mm}$ from the posterior descending artery. This incision was started at the midportion of the inferior wall and extended proximally toward the mitral anulus and distally toward the apex of the ventricle. Stay sutures were passed through the fat pad of the apex of the ventricle and margins of the ventriculotomy to facilitate exposure of the ventricular cavity. The VSD was carefully located; it was found in the proximal half of the posterior septum in most cases. The posteromedial papillary muscle was involved by the infarction in all patients. A bovine pericardial patch was tailored in a triangular shape of approximately $4 \times 7 \mathrm{~cm}$ in most patients. The base of the triangular-shaped patch was sutured to the fibrous anulus of the mitral valve with a 

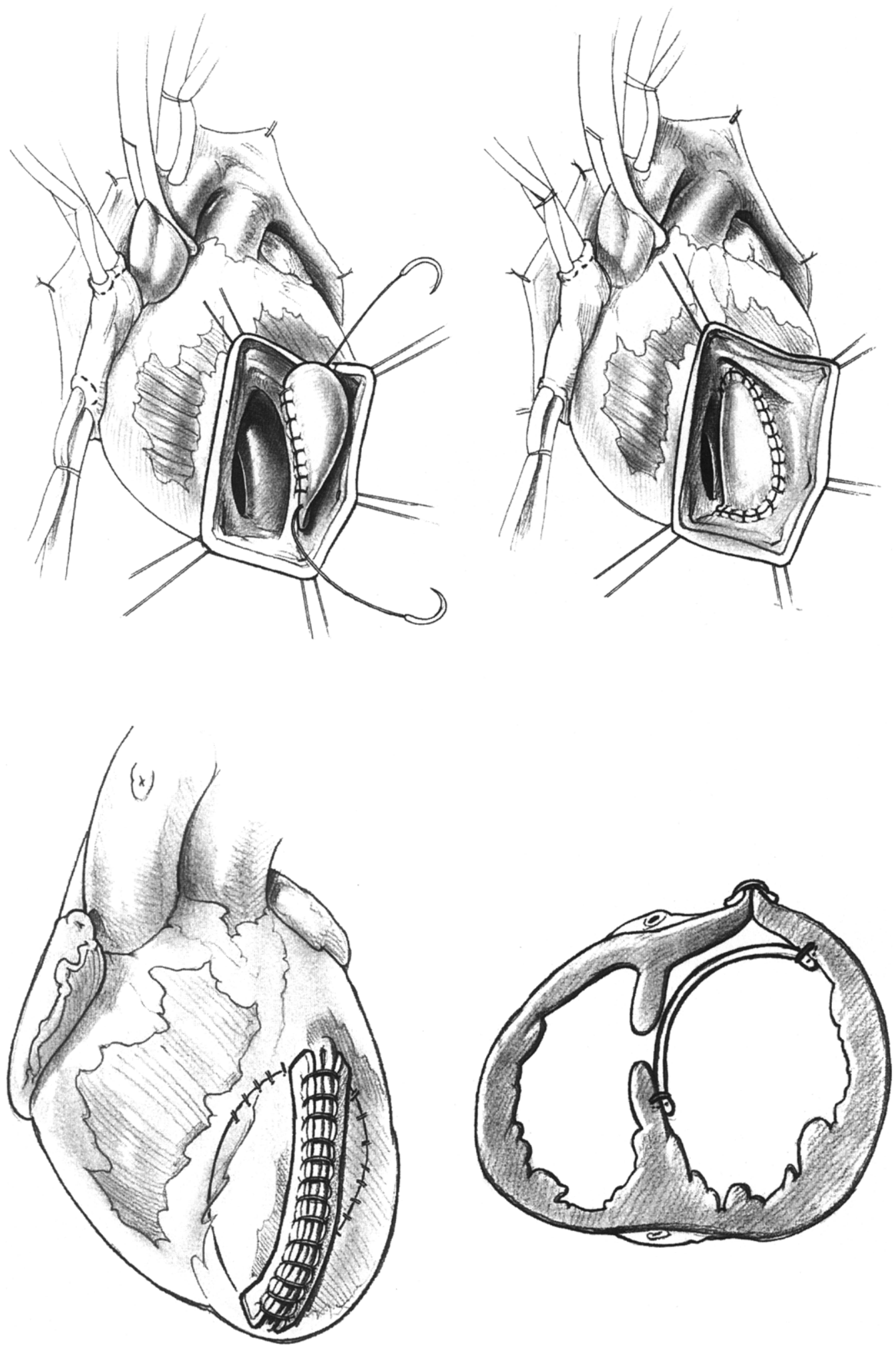

Fig. 1. Repair of anterior VSD by endocardial patch with infarct exclusion. Pericardial patch is sutured to septum first then to lateral wall. 
continuous 3-0 polypropylene suture starting at a point corresponding to the level of the posteromedial papillary muscle and moving medially toward the septum until the noninfarcted endocardium was reached. At that level, the suture was interrupted and any excess patch material was trimmed. The medial margin of the triangular-shaped patch was sewn to healthy septal endocardium with a continuous suture. The lateral side of the patch was sutured to the posterior wall of the left ventricle along a line corresponding to the medial margin of the base of the posteromedial papillary muscle. Because the posterior wall of the left ventricle was infarcted, it was necessary to use full-thickness bites and anchor the sutures on a strip of pericardium or Teflon felt applied on the epicardial surface of the posterior wall of the left ventricle as shown in Fig. 2. Once the patch was completely sutured to the mitral valve anulus, the endocardium of the interventricular septum, and the full thickness of the posterior wall, the ventriculotomy was closed in two layers of sutures buttressed on strips of pericardium or Teflon felt. The infarcted right ventricular wall was left undisturbed. In one patient one head of the posteromedial papillary muscle had ruptured and repair was accomplished by reattaching it with a 5-0 expanded polytetrafluoroethylene suture secured to the infarcted papillary muscle and also by anchoring the suture in a pledget on the epicardial surface of the posterior wall. The mean aortic crossclamp time was $65 \pm 20$ minutes (range 29 to 98 minutes) and the mean cardiopulmonary bypass time was $92 \pm 28$ minutes (range 45 to 184 minutes).

\section{Results}

There were six operative deaths. Two patients could not be weaned from cardiopulmonary bypass and died in the operating room; four patients died postoperatively between 1 and 44 days. One patient died as a result of rupture of the free wall on the day after operation. In another patient severe mitral regurgitation as a result of rupture of the posteromedial papillary muscle developed 5 weeks later; the patient required mitral valve replacement and died. One had a stroke 6 weeks after operation during hemodialysis required because of renal failure; one had a cardiac arrest 4 weeks after operation and could not be resuscitated. Postoperative complications were common: 35 patients required therapy with inotropes because of low cardiac output syndrome; 10 required renal dialysis because of acute tubular necrosis; and 18 required prolonged ( $>48$ hours) assisted ventilation. The mean intensive care unit (ICU) stay was $10 \pm 18$ days (range 1 to 112 days), and the mean hospital stay was $22 \pm 24$ days ( 1 to 131 days). The ICU stay was $7 \pm 9$ days for operative survivors and $26 \pm 40$ days for nonsurvivors; it was $3 \pm 4$ days for patients in hemodynamically stable condition and $13 \pm 17$ days for patients in cardiogenic shock.
Univariate analysis identified cardiogenic shock and severe right ventricular dysfunction as predictors of operative mortality; by multivariate analysis only severe right ventricular dysfunction was predictive of operative mortality. Table III shows the operative mortality in various subgroups of patients.

Patients have been followed up from 3 to 95 months, with a mean of $40 \pm 34$ months. No patient has been lost to follow-up. There have been six late deaths: congestive heart failure in two patients, myocardial infarction in one, stroke in one, cancer in one, and unknown in one. Fig. 3 shows the actuarial survival, which was $66 \% \pm 7 \%$ at 6 years. The following variables were predictive of early plus late mortality by univariate analysis: left ventricular dysfunction $(p<0.04)$ and renal failure $(p<0.03)$. Only the latter was predictive of mortality by multivariate analysis $(p<0.05)$.

All patients have had Doppler echocardiographic studies postoperatively at least once a year. Only one patient has a small residual VSD (shunt $<$ 1.5:1). Table IV shows the latest postoperative left and right ventricular function as assessed by echocardiography. At the most recent follow-up, 17 patients were in New York Heart Association functional class I, 14 in class II, and 1 in class III.

\section{Discussion}

Although the ideal time to operate on patients with postinfarction VSD is after the necrotic muscle has been replaced by fibrous tissue, this is not possible in most patients because heart failure or cardiogenic shock, or both, develop and the patients die unless surgically treated. ${ }^{6,13}$ Thus we believe that these patients should be operated on urgently if they are in hemodynamically stable condition and immediately if they are in cardiogenic shock. Postponing operation only increases the operative risk because often renal failure and other organ dysfunction develop in these patients.

Cardiogenic shock has been identified as the single most important determinant of operative mortality in many series. ${ }^{6,12,14,15}$ Cardiogenic shock in patients with postinfarction VSD is caused by various factors, but right ventricular dysfunction has been identified as one of the most important, particularly in patients with posterior VSD who often have extensive right ventricular infarction. $6,16-19$ Cummings and associates ${ }^{17}$ performed a quantitative analysis of acute right and left ventricular infarction in 15 autopsied hearts with acute postinfarction VSD and found that with anterior VSD 
The Journal of Thoracic and

Gardiovascular Surgery

David, Dale, Sun 1319

Volume 110, Number 5
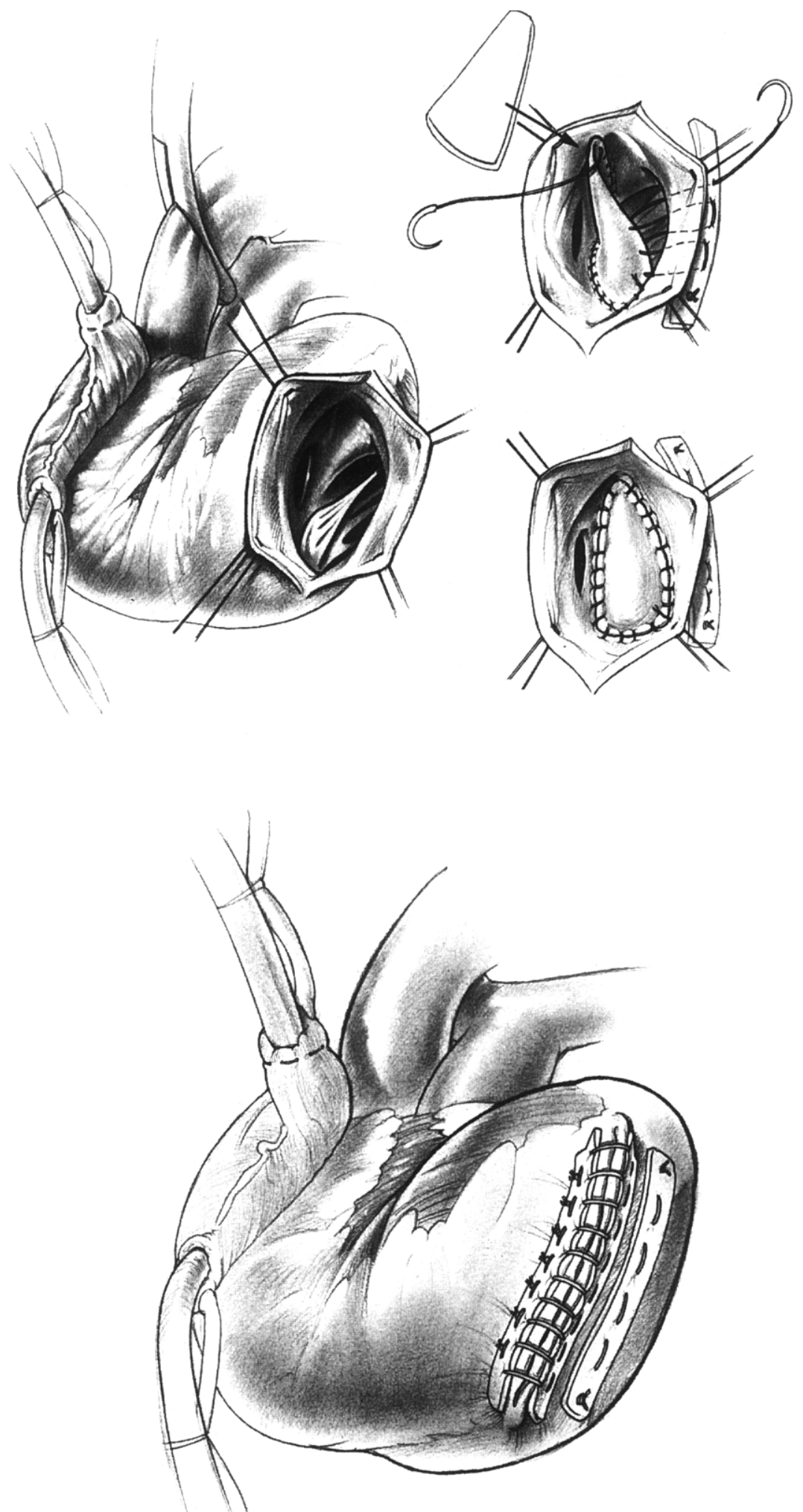

Fig. 2. Repair of posterior VSD by endocardial patch with infarct exclusion. Pericardial patch is sutured to mitral anulus, septum, and posterior wall. 


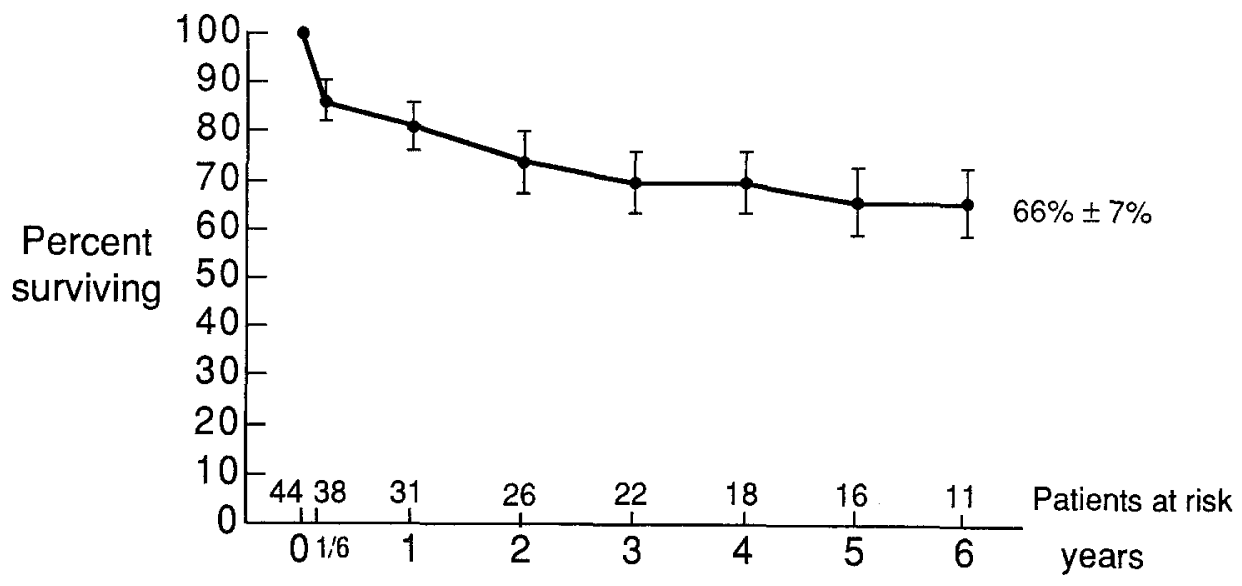

Fig. 3. Actuarial survival after repair of postinfarction VSD.

Table III. Operative mortality

\begin{tabular}{ll}
\hline \multicolumn{1}{c}{ Variable } & Mortality (\%) \\
\hline Age & $5 / 29(17.2)$ \\
$>70 \mathrm{yr}$ & $1 / 17(5.8)$ \\
$<71$ yr & $3 / 22(13.6)$ \\
Anterior VSD & $3 / 22(13.6)$ \\
Posterior VSD & \\
Left ventricular function & $1 / 9(11.1)$ \\
$\quad$ Grade 2 & $3 / 28(10.7)$ \\
Grade 3 & $2 / 7(28.5)$ \\
Grade 4 & \\
Right ventricular & $0 / 10(0)$ \\
Grade 2 & $1 / 24(4.1)^{*}$ \\
Grade 3 & $5 / 10(50)^{*}$ \\
Grade 4 & \\
Coronary artery disease & $2 / 12(16.6)$ \\
Single vessel & $4 / 32(12.5)$ \\
Two and three vessel & \\
Cardiogenic shock & $6 / 29(20.6)^{*}$ \\
Yes & $0 / 15(0)^{*}$ \\
No & \\
Renal failure & $4 / 13(30.7)^{*}$ \\
Yes & $2 / 31(6.4)^{*}$ \\
No &
\end{tabular}

"Denotes statistically significant differences.

$32.3 \% \pm 9.9 \%$ of the left ventricle and $9.9 \% \pm 3.1 \%$ of the right ventricle were infarcted; with posterior VSD $21.3 \% \pm 6.3 \%$ of the left ventricle and $31.4 \% \pm 23.2 \%$ of the right ventricle were infarcted. These investigators also compared these figures with those of autopsied hearts with acute anterior and inferior myocardial infarction without VSD and found that the amount of right ventricular infarction was more extensive in patients with VSD. ${ }^{17} \mathrm{Ze}$ hender and associates ${ }^{20}$ found that inferior wall infarction carries a higher mortality when associated
Table IV. Postoperative left and right ventricular function

\begin{tabular}{lcc}
\hline & $\begin{array}{c}\text { Left ventricle } \\
(\%)\end{array}$ & $\begin{array}{c}\text { Right ventricle } \\
(\%)\end{array}$ \\
\hline Normal & $1(3)$ & $19(59)$ \\
Mild impairment & $13(41)$ & $11(34)$ \\
Moderate impairment & $16(50)$ & $1(3)$ \\
Severe impairment & $2(6)$ & $1(3)$ \\
\hline
\end{tabular}

with right ventricular infarction in patients without VSD. Hence the outcome of patients with postinfarction VSD is largely related to the size of the right ventricular infarct. We believe this is particularly true for patients with posterior VSD; for patients with anterior VSD the size of the left ventricular infarct is also important as shown in Tables II and III.

The observations made by Cummings ${ }^{17}$ and $\mathrm{Ze}$ hender ${ }^{20}$ and their associates demonstrate the importance of right ventricular infarction and dysfunction in patients with acute myocardial infarction. Traditional operative techniques for patients with postinfarction VSD consisted of infarctectomy and reconstruction of the left and right ventricular walls with Dacron fabric graft. ${ }^{8-10}$ These procedures likely increased right and left ventricular dysfunction and consequently were associated with high operative mortality. ${ }^{8-10,14,18,19}$ The operative mortality rate in most series ranged from $35 \%$ to $50 \% .^{11,14,18,19}$ The only exception was the series of 101 patients reported on by Skillington and colleagues ${ }^{15}$ in which the overall mortality rate was $20.8 \%$ and was reduced to only $11.1 \%$ in their most recent 36 patients. 
We believe the technique of endocardial patch with infarct exclusion as described in this report is physiologically sound and should enhance operative survival because it leaves the right ventricle undisturbed and restores the geometry of the left ventricle in these patients with acutely infarcted myocardium and ruptured septum. Infarct expansion is common after transmural myocardial infarction and patients in whom a VSD develops often have an acute ventricular aneurysm. Restoration of left ventricular geometry has been shown to be important for left ventricular function. ${ }^{21-23}$

Although cardiogenic shock is an important determinant of operative mortality, it does not affect long-term outcome of operative survivors. Other factors such as left ventricular function, renal failure, and extensiveness of the coronary artery disease are more important. ${ }^{12,24}$ Some surgeons believe that coronary angiography is not necessary in patients in cardiogenic shock, ${ }^{14,15}$ but we and others have found that concomitant myocardial revascularization in patients with multivessel disease decreases operative mortality and improves long-term survival. ${ }^{12,21,24}$ Therefore patients in shock should be expeditiously treated with intraaortic balloon pump, vasodilators, inotropes, and, if necessary, assisted ventilation before being transferred to the angiography suite. Operation should be done immediately after angiography.

Patients with postinfarction VSD require considerable hospital resources, particularly when they are admitted to the hospital already in cardiogenic shock. The mean ICU stay was 10 days for all patients in our series; it was only 3 days for patients in hemodynamically stable condition and 13 days for patients in cardiogenic shock. More important, the mean ICU stay was only 7 days for operative survivors and 29 days for nonsurvivors.

Although our experience is limited to 44 patients, repair of acute postinfarction VSD by endocardial patch with infarct exclusion of the left ventricle probably avoids additional damage to the already dysfunctional right ventricle, remodels the left ventricle by eliminating the often dyskinetic infarcted left ventricle, and enhances survival.

\section{REFERENCES}

1. Honan MB, Harrell FE Jr, Reimer KA, et al. Cardiac rupture, mortality and timing of thrombolytic therapy: a meta-analysis. J Am Coll Cardiol 1990;16:359-67.

2. Fencley M, Chang VP, O'Rourke MF. Myocardial rupture after acute myocardial infarction: ten year review. Br Heart J 1983;49:550-6.

3. Vlodacer Z, Edwards JE. Rupture of ventricular septum and papillary muscle complicating myocardial infarction. Circulation 1977;55:815-22.

4. Reddy SG, Roberts WC. Frequency of rupture of the left ventricular free wall and ventricular septum among necropsy cases of fatal acute myocardial infarction since introduction of coronary care units. Am J Cardiol 1989;63:906-11.

5. Sanders RJ, Kern WH, Blount SG Jr. Perforation of the interventricular septum complicating myocardial infarction. Am Heart J 1956;51:736-48.

6. Raddford MJ, Johnson RA, Daggett WM Jr, et al. Ventricular septal rupture: a review of clinical and physiologic features and an analysis of survival. Circulation 1981;64:545-53.

7. Estrada-Quintero R, Uretsky BF, Murali S, Hardesty RL. Prolonged intra-aortic balloon support for septal rupture after myocardial infarction. Ann Thorac Surg 1992;53:335-7.

8. Giuliani E, Danielson G, Pluth J, et al. Postinfarction ventricular septal rupture: surgical considerations and results. Circulation 1974;49:455-9.

9. Daggett WM, Guyton RA, Mundth ED, et al. Surgery for postinfarct ventricular septal defect. Ann Surg 1977;203:269-71.

10. Daggett WM. Surgical technique for early repair of posterior ventricular septal rupture. J THORAC CARDIOVASC SURG 1982;84:306-12.

11. David TE. Surgical treatment of postinfarction ventricular septal rupture. Australas J ThoraC CARDIOVASC SURG 1992;1:7-10.

12. Komeda M, David TE, Fremes SE. Surgical repair of postinfarction ventricular septal defect. Circulation 1990;82(Suppl):IV243-7.

13. Kirklin JW, Barratt-Boyes BG, eds. Cardiac surgery: postinfarction ventricular septal defect. New York: Churchill Livingstone, 1993:403-13.

14. Deville C, Fontan F, Chevalier JM, et al. Surgery for postinfarction ventricular septal defect: risk factors for hospital death and long-term results. Eur J Cardiothorac Surg 1991;5:167-75.

15. Skillington PD, Lamb RD, Monro JL, et al. Surgical treatment of infarct related ventricular septal defects: improved early results combined with analysis of late functional status. J Thorac Cardrovasc Surg 1990; 99:798-808.

16. Fanapazir L, Bray CL, Dark JF, et al. Right ventricular dysfunction and surgical outcome in postinfarction ventricular septal defect. Eur Heart J 1983;4:155-67.

17. Cummings RG, Reimer KA, Califf R, et al. Quantitative analysis of right and left ventricular infarction in the presence of postinfarction ventricular septal defect. Circulation 1998;77:33-42.

18. Moore CA, Nygaard TW, Kaiser DL, et al. Postin- 
farction ventricular septal rupture: the importance of location of infarction and right ventricular function in determining survival. Circulation 1986;74:45-55.

19. Cummings RG, Califf R, Jones RN, et al. Correlates of survival in patients with postinfarction ventricular septal defect. Ann Thorac Surg 1989;47:824-30.

20. Zehender M, Kasper W, Kauder E, et al. Right ventricular infarction as an independent predictor of prognosis after acute inferior myocardial infarction. $\mathrm{N}$ Engl J Med 1993;328:981-8.

21. David TE. Surgery for postinfarction ventricular septal defect. In: David TE, ed. Mechanical complications of myocardial infarction. Austin, Texas: RG Landes, 1993:175-91.

22. Jatene AD. Left ventricular aneurysmectomy: resection or reconstruction. J THORAC CARdiovasc Surg 1985;89:321-31.

23. Di Donato M, Barletta G, Maioli M, et al. Early hemodynamic results of left ventricular reconstructive surgery for anterior wall left ventricular aneurysm. Am J Cardiol 1992;69:886-90.

24. Muehrcke DD, Daggett WM Jr, Buckley MJ, et al. Postinfarction ventricular septal defect repair: effect of coronary artery bypass grafting. Ann Thorac Surg 1922;54:876-83.

\section{Discussion}

Dr. William M. Daggett (Boston, Mass.). I find myself in the unenviable but inevitable position of seeing my own work with this lesion become of historical interest only. It is appropriate that this new operation for ventricular septal rupture comes from Toronto where Dr. Raymond Heimbecker made such important early contributions to the operative treatment of this lesion. The results achieved by Dr. David and his co-workers with this new operation of infarct exclusion with a baffle are, I believe, unmatched, with the possible exception of those of Skillington and his co-workers from Southampton.

Our own experience with ventricular septal rupture and particularly posterior septal rupture totals 91 patients with a hospital survival for the entire series of $75 \%$. Actuarial survival at 5 years is approximately $60 \%$. Nevertheless, we have been unable to match the low hospital mortality rate of $14 \%$ achieved by Dr. David with his new operation, which is an extension to patients with ventricular septal rupture of the concept of left ventricular endoaneurysmorraphy proposed by Dr. Dor and to which both Dr. Cooley and Dr. David have made significant contributions. I am unable to decide whether the results that Dr. David has been able to achieve are a result of the design of the operation or of his surgical skill. I suspect both have contributed to these brilliant results. The achievement of a lower hospital mortality and shorter length of stay in these perilous times of managed health care is a real breakthrough with a complex surgical problem. It will be interesting to follow outcomes of patients operated on in other centers with this new technique. Finally, I would like to support Dr. David's position that long-term survival is significantly enhanced in patients who undergo complementary coronary bypass grafting at the time of ventricular septal rupture repair.

I have one brief question. Have the authors used autologous pericardium for the baffle in any of the cases?

Dr. David. Thank you, Dr. Daggett. I think your contribution to work with ruptured septum goes far beyond historical interest. You continue to contribute to our understanding and management of this condition.

I believe this technique is reproducible. My associates have been using it and agree that it is the best surgical approach. It prevents damage to the right ventricle, which is often extensively infarcted, and it remodels the left ventricle. Left ventricular remodeling is important for ventricular function in patients with acute transmural myocardial infarction.

I have never used autologous pericardium, but one of my associates, Dr. Feindel, uses it routinely. I have not used autologous pericardium because I had reconstructed chronic aneurysms with autologous pericardium and over the years found it to bulge again. For this reason, I prefer to use glutaraldehyde-fixed bovine pericardium.

Dr. Vincent Dor (Monte Carlo, Monaco). I want to support Dr. David strongly in his proposition to use a patch to exclude the diseased portion of the septum and of the left ventricle in this type of mechanical complication of myocardial infarction.

We have a similar experience with anterior rupture that extends 10 years. Among the advantages of the endoventricular circular patch plasty, we have pointed out the possibility of placing the patch above the rupture, approaching the lesion through the infarcted area, and creating a neo-apex of the left ventricle with treatment both of the lesion by exclusion and of the dyskinesia.

We presented such a case at this meeting in 1992, and the patient is still alive and well 8 years after operation. The rupture was on the medial part of the septum, and the ventricle was totally rebuilt by a patch excluding the septum.

Our series consists of 12 cases with only one failure with anterior rupture; I know Dr. Menicanti in Milan has an experience of 8 cases. I support this technique of a patch to restore the left ventricular cavity. 